\title{
Ultrasonographic optic nerve sheath diameter correlation with ICP and accuracy as a tool for noninvasive surrogate ICP measurement in patients with decompressive craniotomy
}

\author{
*Juxiang Wang, MD,,${ }^{1,2} \mathrm{Ke} \mathrm{Li,} \mathrm{PhD,}{ }^{3}$ Hongjia Li, MBBS, ${ }^{4}$ Chengyi Ji, MBBS, ${ }^{2}$ Ziyao Wu, MBBS, ${ }^{2}$ \\ Huimin Chen, MBBS, ${ }^{2}$ and Bin Chen, PhD $^{5}$ \\ 1Department of Intensive Care Unit, Xiamen Cardiovascular Hospital, Xiamen University; '2Department of Intensive Care Unit, \\ Third Hospital of Xiamen Affiliated of Fujian University of Traditional Chinese Medicine; '3Department of Intensive Care Unit, \\ Xiang'an Hospital of Xiamen University; ${ }^{4}$ Department of Neurosurgery, Third Hospital of Xiamen Affiliated of Fujian University of \\ Traditional Chinese Medicine; and ${ }^{5}$ Department of Healthcare, Xiamen Port Clinic of Xiamen Customs, Xiamen, Fujian, China
}

OBJECTIVE Increased intracranial pressure (ICP) results in enlarged optic nerve sheath diameter (ONSD). In this study the authors aimed to assess the association of ONSD and ICP in severe traumatic brain injury (TBI) after decompressive craniotomy (DC).

METHODS ONSDs were measured by ocular ultrasonography in 40 healthy control adults. ICPs were monitored invasively with a microsensor at 6 hours and 24 hours after DC operation in 35 TBI patients. ONSDs were measured at the same time in these patients. Patients were assigned to 3 groups according to ICP levels, including normal (ICP $\leq 13 \mathrm{~mm}$ $\mathrm{Hg}$ ), mildly elevated (ICP $=14-22 \mathrm{~mm} \mathrm{Hg}$ ), and severely elevated (ICP $>22 \mathrm{~mm} \mathrm{Hg}$ ) groups. ONSDs were compared between healthy control adults and TBI cases with DC. Then, the association of ONSD with ICP was analyzed using Pearson's correlation coefficient, linear regression analysis, and receiver operator characteristic curves.

RESULTS Seventy ICP measurements were obtained among 35 TBI patients after DC, including 25, 27, and 18 measurements in the normal, mildly elevated, and severely elevated ICP groups, respectively. Mean ONSDs were $4.09 \pm$ $0.38 \mathrm{~mm}$ in the control group and $4.92 \pm 0.37,5.77 \pm 0.41$, and $6.52 \pm 0.44 \mathrm{~mm}$ in the normal, mildly elevated, and severely elevated ICP groups, respectively $(p<0.001)$. A significant linear correlation was found between ONSD and ICP ( $r$ $=0.771, p<0.0001)$. Enlarged ONSD was a robust predictor of elevated ICP. With an ONSD cutoff of $5.48 \mathrm{~mm}$ (ICP > 13 $\mathrm{mm} \mathrm{Hg}$ ), sensitivity and specificity were $91.1 \%$ and $88.0 \%$, respectively; a cutoff of $5.83 \mathrm{~mm}$ (ICP > $22 \mathrm{~mm} \mathrm{Hg}$ ) yielded sensitivity and specificity of $94.4 \%$ and $81.0 \%$, respectively.

CONCLUSIONS Ultrasonographic ONSD is strongly correlated with invasive ICP measurements and may serve as a sensitive and noninvasive method for detecting elevated ICP in TBI patients after DC.

https://thejns.org/doi/abs/10.3171/2019.4.JNS183297

KEYWORDS ultrasonography; ONSD; optic nerve sheath diameter; ICP; intracranial pressure; traumatic brain injury; DC; decompressive craniotomy; trauma

$\mathrm{E}$ LEVATED intracranial pressure (ICP) is one of the most common symptoms encountered in a variety of traumatic injuries and diseases. ${ }^{28}$ Any tissue swelling within the rigid confines of the skull results in increased ICP, which may lead to life-threatening structural alterations in the brain or cerebral blood flow, thus causing oxygen deprivation and ischemia in the brain. ${ }^{29,30}$
Methods for ICP monitoring can be divided into invasive and noninvasive approaches. In fluid-based systems, external ventricular drainage (EVD) has been considered the gold standard..$^{14}$ Microtransducers for ICP monitoring are just as accurate as EVDs, ${ }^{14}$ and a microsensor was the standard reference method for ICP measurement in this study. The microtransducers also have lower infection and

ABBREVIATIONS DC = decompressive craniotomy; EVD = external ventricular drainage; $G C S=$ Glasgow Coma Scale; $I C P=$ intracranial pressure; $O N S D=$ optic nerve sheath diameter; ROC = receiver operating characteristic; TBI = traumatic brain injury; US-ONSD = ultrasonographic ONSD.

SUBMITTED November 21, 2018. ACCEPTED April 29, 2019.

INCLUDE WHEN CITING Published online July 19, 2019; DOI: 10.3171/2019.4.JNS183297.

${ }^{*}$ H.C. and B.C. contributed equally to this work. 
hemorrhage rates than EVDs but are more expensive., ${ }^{1,24}$ Lumbar puncture also entails the risk of herniation in intracranial hypertension patients. Clinicians have found several noninvasive methods that can be used as surrogates for invasive methods for ICP measurement. ${ }^{21,22,26}$ The optic nerve, as part of the central nervous system, is wrapped by the dural sheath. The optic nerve sheath (ONS) is the continuation of the subarachnoid space at the optic nerve, and its tissues are connected with the subarachnoid space..$^{13}$ Thus, an increase in ICP results in a corresponding elevation of the ONS diameter (ONSD). ${ }^{26}$ During an autopsy in 1996, Hansen et al. found that in untreated human cadaveric specimens the widest region of the ONS is located $3 \mathrm{~mm}$ behind the eyeball and ranges between 2.1 and $4.8 \mathrm{~mm}$, reaching the maximum value of $6.5 \mathrm{~mm}$ when fluid is injected into the subarachnoid space. ${ }^{13}$ With the use of a B-mode ultrasound system and a 4-12-MHz line array probe, the ONSD appears as a linear and well-defined hypoechoic region behind the eyeball. ${ }^{12}$ In this study the ONSDs were measured by ocular ultrasonography in healthy adults and traumatic brain injury (TBI) patients after decompressive craniotomy (DC), and ICPs were monitored by invasive microsensor at the same time as ultrasonography in DC patients in this study. In this study we aimed to assess the relationship between ultrasonographic ONSD (US-ONSD) and invasive ICP and assess the feasibility and clinical value of US-ONSD for the detection of elevated ICP in these patients.

\section{Methods \\ Patients}

Inclusion criteria for healthy volunteers were age $\geq$ 18 years, without a history of neurological disorders, hyperthyroidism, chronic obstructive pulmonary disease, or optic neuropathy. Inclusion criteria for patients with TBI were brain-injured patients age $\geq 18$ years, with intracranial hematoma/diffuse brain contusion, indications for emergency operation, emergent intervention for craniotomy, and evacuation of hematoma, as well as DC, intraoperative placement of ICP monitoring with cathetertip pressure microsensors, prolonged ICU treatment, and admission to the surgical ICU of the Third Hospital of Xiamen between January 2017 and May 2018. Exclusion criteria were spinal cord injury, orbital injury, optic nerve injury, cardiopulmonary resuscitation after cardiac arrest, meningitis, optic neuritis, ${ }^{22}$ diabetic ketoacidosis, ${ }^{32}$ carbon dioxide retention, ${ }^{28}$ and survival time less than 24 hours after operation. The current study was approved by the local ethics committee of the Third Hospital of Xiamen and performed according to the ethical standards of the latest revision of the Declaration of Helsinki. Before patient enrollment, written informed consent was obtained from family members or responsible parties.

\section{Treatment Methods}

Primary DC was performed in patients with TBI, according to injury mechanisms, clinical manifestations, Glasgow Coma Scale (GCS) score, and CT data. Unilateral DC was performed on the cerebral hemisphere that had a hematoma; bilateral decompression or anterior decom- pression was carried out instead when both hemispheres had hematomas or a frontal lobe lesion occurred..$^{16}$ Patients with diffuse brain injury and intractable intracranial hypertension also underwent DC. ${ }^{9}$ The incision was extended to the edge of the bone window and the dura mater, using arcuate incisions. Then, the hematoma, necrotic brain tissue, and blood clots were removed to ensure effective hemostasis. The remaining dura or artificial dura substitutes without a watertight closure were used to loosely cover the brain surface. The ICP monitoring device Codman MicroSensor transducer (Johnson \& Johnson Inc.), one of the microtransducers used for ICP monitoring, was positioned at the decompressed side in selected cases based on the advice from attending neurosurgeons. After the operation, a Codman ICP Express cranial monitor (Johnson \& Johnson Inc.) was used to monitor ICP. The ICP value measured by this method was used as a standard reference.

\section{Ultrasound Measurements}

The studies were carried out on a 4-12-MHz linear transducer using Vivid-Q (General Electric Vingmed Ultrasound). US-ONSD measurements were performed in patients in the semisupine position with the head raised by $20^{\circ}-30^{\circ}$. The patient's eyes were closed and the ultrasonic couplant was applied to the upper eyelid. The probe was gently placed over it to avoid pressing the eyeball. Horizontal sections of the eyeball were measured by scanning from the superior to the inferior side. The section showing the maximal transverse diameter of the eyeball was frozen. The ONSD appeared as a linear, well-defined hypoechoic region. ONSD was assessed $3 \mathrm{~mm}$ behind the globe, and the diameter was measured with an electronic caliper, ${ }^{27}$ perpendicularly to the optic nerve sheath (Fig. 1). The recorded ONSD was the mean value of 3 measurements, and both the left and right ONSDs were recorded. US-ONSDs were carried out by two critical care medicine physicians (J.W. and Z.W.). Before the study, both physicians were intensely trained by performing ONSD measurement no less than 30 times. They mastered the examining methods and crosschecked their data. Healthy volunteers were subjected to ultrasound measurement of ONSD at the steady state. The enrolled patients underwent US-ONSD and ICP 6 hours and 24 hours after DC. The patients were simultaneously administered appropriate sedative and analgesic treatments under normal partial pressure of carbon dioxide, avoiding stimulating procedures such as mucus suction and turning over. No dehydration treatment was administered 2 hours before the measurement. Two sets of data (at 6 hours and 24 hours after DC) were obtained from each patient. Meanwhile, GCS and ICP were evaluated and recorded by the attending physician. The measurements of ONSD and ICP were carried out simultaneously. All of the collected data were eventually sent to the principal investigator. The expert ultrasound operators were blinded to patient ICP values. Meanwhile, ONSD measurement data were not sent to the attending physician, thus preventing these results from affecting clinical judgment.

\section{Data Collection and Patient Grouping}

The bilateral ONSD values of healthy volunteers were 

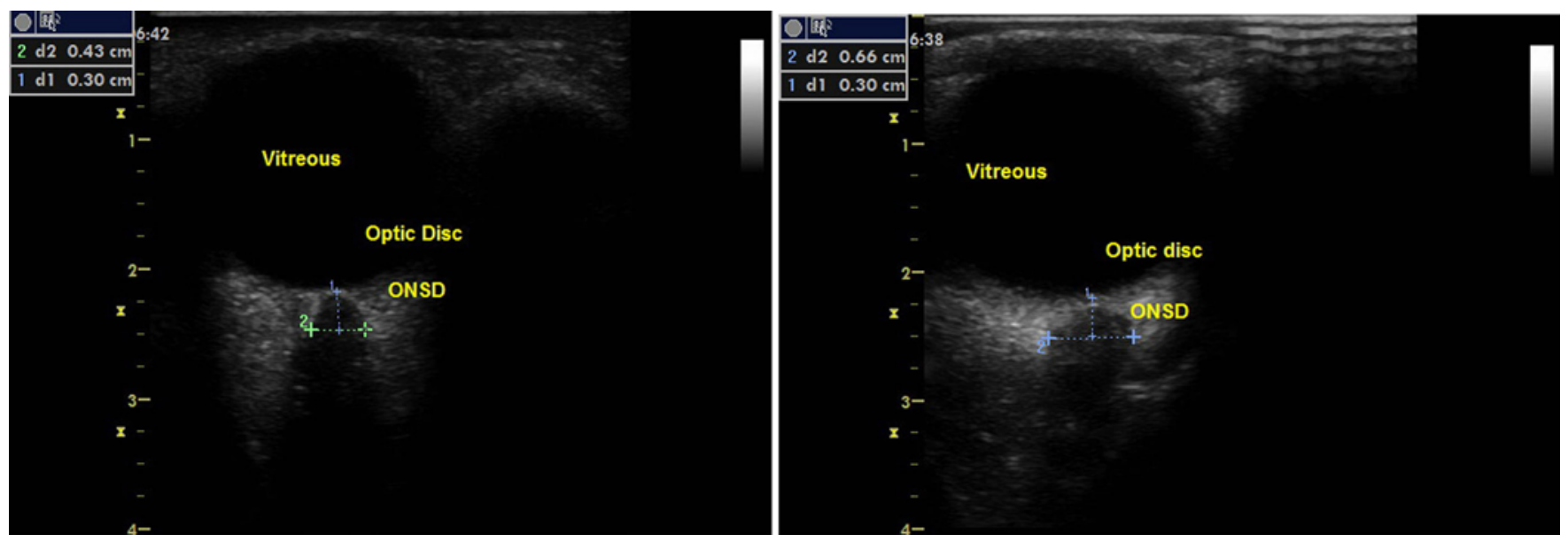

FIG. 1. Normal diameter of the optic nerve sheath (left). Increased diameter of the optic nerve sheath (right). Figure is available in color online only.

collected, in addition to baseline characteristics such as sex, age, height, and BMI. In addition to these baseline characteristics, patient data included the cause and nature of brain injury, as well as the interval from admission to emergency surgery. US-ONSD, ICP, and GCS score were measured 6 and 24 hours after the DC operation. According to the American guidelines for TBI, ${ }^{6}$ patients with ICP above $22 \mathrm{~mm} \mathrm{Hg}$ following brain injury require clinical intervention. Based on critical ICP values, i.e., 13 and 22 $\mathrm{mm} \mathrm{Hg}$, patients with TBI are generally subdivided into 3 groups, including the normal (ICP $\leq 13 \mathrm{~mm} \mathrm{Hg}$ ), mildly elevated (ICP 14-22 $\mathrm{mm} \mathrm{Hg}$ ), and severely elevated (ICP $>22 \mathrm{~mm} \mathrm{Hg}$ ) ICP groups.

\section{Statistical Analysis}

Statistical analyses were conducted on IBM SPSS Statistics 20.0. After assessment for normality, the point estimation values that were normal distributions were expressed as mean \pm standard deviation (SD). For nonnormal distributions, the values were expressed as median and range of minimum to maximum. The parametric comparisons were performed by using a two-tailed Student t-test for normal distributions. Proportions were analyzed with the chi-square test. Correlations between the variables were based on the Pearson's correlation coefficient. The diagnostic accuracy of raised ICP and the optimal thresholds for detecting elevated ICP for US-ONSD were derived from receiver operating characteristic (ROC) analysis; $p<0.05$ was considered statistically significant.

\section{Results Interobserver Variability}

Before the study, 2 ICU physicians who were the ultrasound operators (J.W. and Z.W.) had assessed 25 healthy volunteers and 15 TBI patients, and after the physicians mastered ONSD measurement, they tested 15 healthy adults and 15 patients again. The observers were blinded to each other's findings. Interobserver variability in ONSD measurement was assessed by comparing US-ONSD between TBI and healthy volunteers. Mean differences were
$0.13 \pm 0.02 \mathrm{~mm}$ and $0.14 \pm 0.02 \mathrm{~mm}$ for the left and right eyes, respectively; the examinations lasted $158.4 \pm 6.05$ seconds (range 110-220 seconds) and $163.2 \pm 7.02$ seconds (110-250 seconds), respectively. Then, the 2 ICU physicians (J.W. and Z.W.) performed US-ONSD in the clinical trials.

\section{Patient Characteristics}

Bilateral ONSDs were examined in a total of 40 healthy volunteers. Meanwhile, 168 patients with TBI were admitted to the ICU and only 35 patients were enrolled in the study. A flowchart of the patient selection process is shown in Fig. 2. The mean ONSD value for the 2 eyes considered for statistical analysis was $4.09 \pm 0.38 \mathrm{~mm}$ in healthy volunteers compared to $5.15 \pm 0.52 \mathrm{~mm}$ in the TBI patients $(\mathrm{p}<0.0001)$. Demographic data for the patients and controls are depicted in Table 1.

\section{Subgroup Analysis of TBI Patients According to ICP}

Of the 70 measurements in patients with TBI, there were 25 (35.72\%), 27 (38.57\%), and 18 (25.71\%) measurements in the normal, mildly elevated, and severely elevated ICP groups, respectively. The mean ONSD value in the normal ICP group was $4.92 \pm 0.37 \mathrm{~mm}$, which was significantly higher than that of healthy adults, $4.09 \pm 0.38 \mathrm{~mm}$ $(\mathrm{p}<0.001)$. There were statistical differences in ICP and ONSD values among the 2 ICP groups $(p<0.001)$. The details of subgroup analysis are shown in Table 2.

\section{Association of ONSD With ICP}

The ICP and ONSD values of patients with TBI were statistically analyzed, and the scatter plot of the correlation between ICP and ONSD was generated and a linear regression trend line was added (Fig. 3). The mean ICP in TBI patients was $18.7 \pm 5.7 \mathrm{~mm} \mathrm{Hg}$, ranging from 7 to $34 \mathrm{~mm} \mathrm{Hg}$. A significant linear correlation was found between ONSD and ICP $(r=0.771, p<0.0001$; Fig. 3$)$.

\section{Value of ONSD for Detecting Elevated ICP}

ONSD accurately predicted an ICP above $13 \mathrm{~mm} \mathrm{Hg}$ 


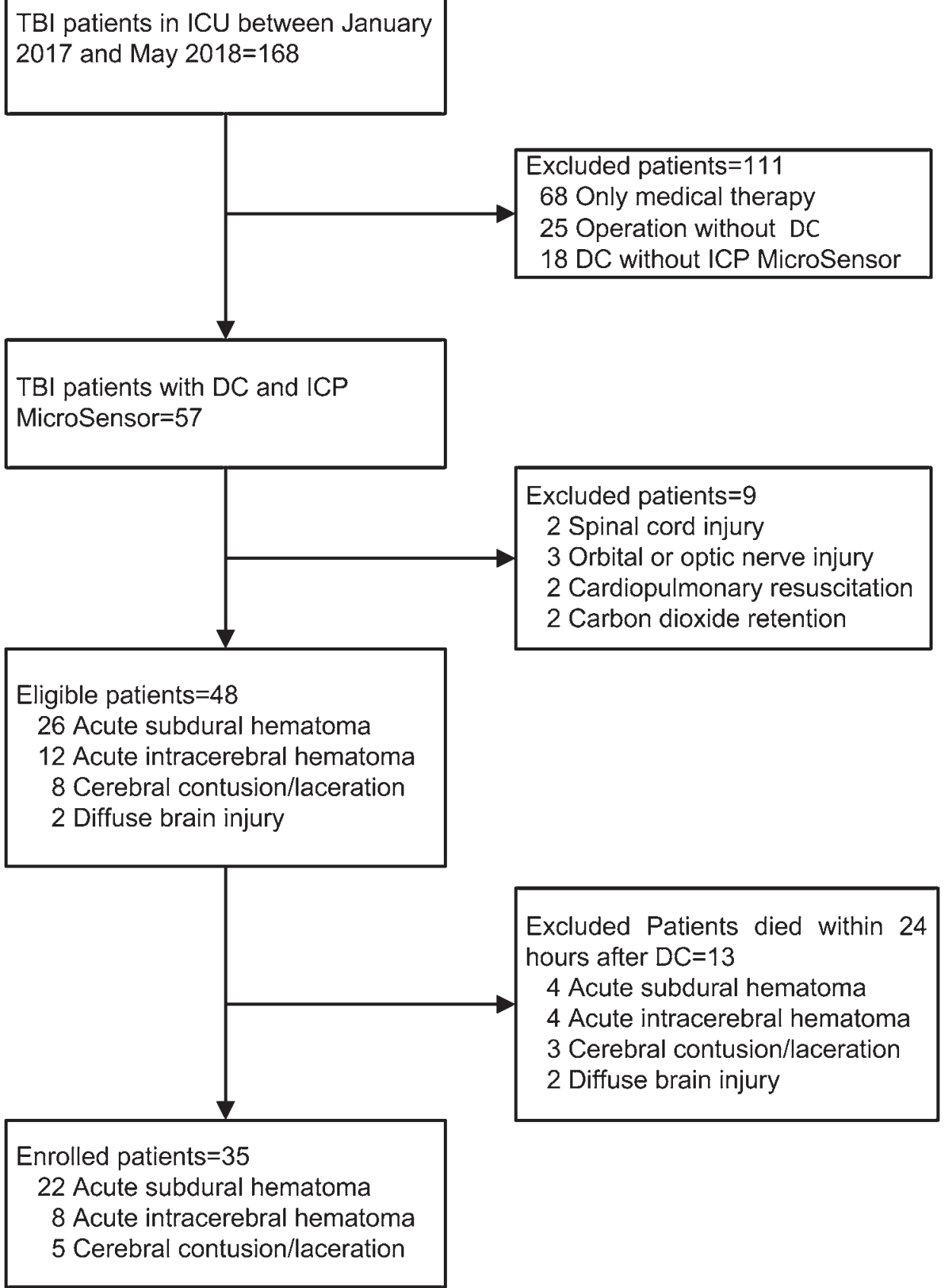

FIG. 2. Flowchart of the patient selection process.

(area under ROC $=0.96 ; 95 \%$ CI 0.915-1.000; $\mathrm{p}<0.0001$; Fig. 4 left). Using ROC analysis, the optimal threshold was set for establishing the likelihood of elevated ICP. The best ONSD cutoff value for detecting elevated ICP above $13 \mathrm{~mm} \mathrm{Hg}$ was $5.48 \mathrm{~mm}$, yielding sensitivity and specificity of $91.1 \%$ and $88.0 \%$, respectively. The negative and positive predictive values were $78.57 \%$ and $91.11 \%$, respectively. ONSD accurately predicted an ICP above 22 $\mathrm{mm} \mathrm{Hg}$ (area under ROC $=0.95,95 \%$ CI $0.906-1.000 ; \mathrm{p}$ $<0.0001$; Fig. 4 right). The best ONSD cutoff value for detecting elevated ICP above $22 \mathrm{~mm} \mathrm{Hg}$ was $5.83 \mathrm{~mm}$, with sensitivity and specificity of $94.4 \%$ and $81.0 \%$, re- spectively. Negative and positive predictive values were $97.67 \%$ and $62.96 \%$, respectively.

\section{Discussion}

In this study, ONSDs were measured in healthy adults and TBI patients to guide ICP evaluation. ONSD in healthy adults was $4.09 \pm 0.38 \mathrm{~mm}$, while in DC patients it was $5.15 \pm 0.52 \mathrm{~mm}$, obviously higher than that of healthy adults. Even with normal ICP (i.e., $\leq 13 \mathrm{~mm} \mathrm{Hg}$ ), DC patients showed higher ONSD than healthy individuals (4.92 $\pm 0.37 \mathrm{~mm}$ vs $4.09 \pm 0.38 \mathrm{~mm}$, respectively). Among 
TABLE 1. Baseline characteristics of patients with TBI and healthy adults

\begin{tabular}{lccc}
\hline \multicolumn{1}{c}{ Variable } & $\begin{array}{c}\text { TBI Patients } \\
(\mathrm{n}=35)\end{array}$ & $\begin{array}{c}\text { Healthy Adults } \\
(\mathrm{n}=40)\end{array}$ & $\begin{array}{c}\mathrm{p} \\
\text { Value }\end{array}$ \\
\hline Male sex & $25(71.43 \%)$ & $29(72.5 \%)$ & 0.532 \\
\hline Age $(\mathrm{yrs})$ & $36.97 \pm 13.04$ & $37.10 \pm 11.03$ & 0.963 \\
\hline Height $(\mathrm{kg})$ & $164.23 \pm 7.38$ & $164.65 \pm 7.17$ & 0.803 \\
\hline BMl $\left(\mathrm{kg} / \mathrm{m}^{2}\right)$ & $23.39 \pm 2.61$ & $23.54 \pm 2.40$ & 0.791 \\
\hline $\begin{array}{l}\text { Time from admission to op } \\
\text { (mins) }\end{array}$ & $89.85 \pm 9.70$ & & \\
\hline Reason for op & & & \\
\hline $\begin{array}{l}\text { Acute subdural hematoma } \\
\text { Acute intracerebral } \\
\text { hematoma }\end{array}$ & $22(62.86 \%)$ & & \\
\hline $\begin{array}{l}\text { Cerebral contusion/lacer- } \\
\text { ation }\end{array}$ & $5(22.86 \%)$ & & \\
\hline $\begin{array}{l}\text { ONSD (mm) } \\
\text { Total ONSD exam time } \\
\text { (sec) }\end{array}$ & $166.51 \pm 25.24$ & $157.50 \pm 24.36$ & 0.121 \\
\hline
\end{tabular}

Values are presented as number of patients (\%) unless otherwise indicated. Mean values are presented \pm SD.

${ }^{*} p<0.05$.

TBI patients following DC surgery, $35.72 \%, 64.28 \%$, and $25.71 \%$ had normal, mildly elevated, and severely elevated ICP values, respectively; the corresponding ONSD values were $4.92 \pm 0.37,5.77 \pm 0.41$, and $6.52 \pm 0.44 \mathrm{~mm}$, respectively. There was an overtly significant and linear correlation between ONSD and ICP $(\mathrm{r}=0.771)$. When the critical value of ONSD was $5.48 \mathrm{~mm}$, sensitivity and specificity for detecting ICP > $13 \mathrm{~mm} \mathrm{Hg}$ were $91.1 \%$ and $88 \%$, respectively; at a value of $5.83 \mathrm{~mm}$, sensitivity and specificity for detecting ICP $>22 \mathrm{~mm} \mathrm{Hg}$ were $94.4 \%$ and $81 \%$, respectively. The ONSD value was relatively stable, and the variation between trained operators was small; hence, ONSD could be used as a noninvasive evaluation index for ICP.

Elevated ICP within 48 hours following TBI is an independent risk factor for mortality and is associated with poor prognosis and neurological dysfunction. ${ }^{2}$ In addition, mortality remarkably increases with ICP from 20 to 30 mm Hg. ${ }^{5}$ In comparison with the previous 2007 guidelines ${ }^{4}$ one of the most remarkable changes in the 2016 Brain Trauma Foundation guidelines is the higher threshold for the treatment of elevated ICP, from 20 to $22 \mathrm{~mm}$ $\mathrm{Hg}$, as ICP $>22 \mathrm{~mm} \mathrm{Hg}$ is associated with increased mortality. ${ }^{6}$ The TBI study conducted by Colton et al. revealed that in patient who undergo timely treatment of intracranial hypertension, ICP continues to decline, resulting in good prognosis for the nervous system and increased survival. ${ }^{8}$ Therefore, ICP monitoring is recommended in patients with severe brain injury to improve prognosis and treatment outcomes and reduce in-hospital mortality. ${ }^{20,29}$

Direct ICP monitoring with an intraventricular device provides more accurate results but is highly invasive and has the risk of infection and bleeding. ${ }^{19,25}$ There was a low rate of usage $(24.5 \%)$ of ICP monitoring devices in severe
TABLE 2. Subgroup analysis of patients with TBI according to ICP

\begin{tabular}{lcccc}
\hline & \multicolumn{3}{c}{ ICP Group } & \\
\cline { 2 - 4 } \multicolumn{1}{c}{ Variable } & Normal & $\begin{array}{c}\text { Mildly } \\
\text { Elevated }\end{array}$ & $\begin{array}{c}\text { Severely } \\
\text { Elevated }\end{array}$ & p Value \\
\hline No. $(\%)$ & $25(35.72)$ & $27(38.57)$ & $18(25.71)$ \\
\hline ICP $(\mathrm{mm} \mathrm{Hg})$ & $7.72 \pm 3.02$ & $17.70 \pm 2.09$ & $26.00 \pm 2.74$ & $0.000^{*}$ \\
\hline ONSD $(\mathrm{mm})$ & $4.92 \pm 0.37$ & $5.77 \pm 0.41$ & $6.52 \pm 0.44$ & $0.000^{*}$ \\
\hline GCS score & $8.76 \pm 2.68$ & $8.70 \pm 2.03$ & $7.0 \pm 2.61$ & $0.040^{*}$ \\
\hline
\end{tabular}

Mean values are presented $\pm S D$

${ }^{*} p<0.05$.

TBI patients with DC in China ${ }^{18}$ due to the high cost of DC, which had to be paid by patients' families. Therefore, noninvasive surrogate methods for detecting elevated ICP are highly useful clinical tools. ${ }^{25}$ ONSD was considered as a novel device for noninvasive prediction of ICP and it showed better diagnostic test accuracy than CT for the detection of elevated ICP. ${ }^{21}$ Ohle et al. indicated that USONSD $\geq 5 \mathrm{~mm}$ shows better diagnostic test accuracy for the detection of elevated ICP than CT criteria such as midline shift, hydrocephalus, effacement of sulci, collapse of ventricles, compression of cisterns, etc. ${ }^{22}$ Robba et al. found that ONSD could be the best way to estimate ICP compared to venous transcranial Doppler of the straight sinus systolic flow velocity and transcranial Doppler of the middle cerebral artery. ${ }^{26} \mathrm{CT}$, MRI, and ultrasound can be used to measure the ONSD. ${ }^{23,27}$ Significantly enlarged CT-measured ONSD (CT-ONSD) indicated elevated ICP even with negative CT scans ${ }^{3}$ and was a stronger predictor of ICP than traditional CT data. ${ }^{27}$ T2-weighted MRImeasured ONSD (MRI-ONSD) was a robust predictor of elevated ICP in patients with severe TBI. ${ }^{11}$ MRI-ONSD and US-ONSD showed a strong positive correlation in idiopathic intracranial hypertension, although different values were obtained using these 2 approaches to assess

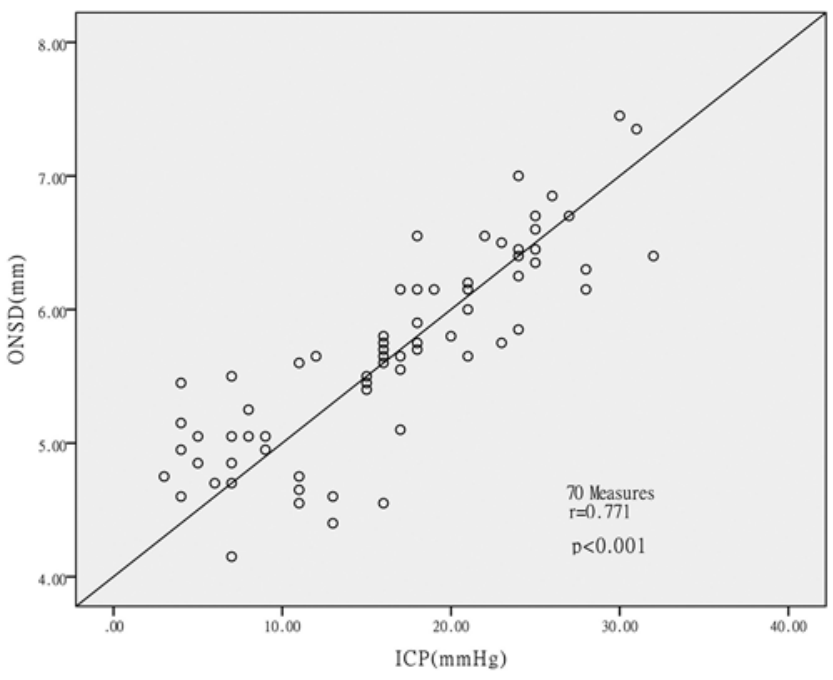

FIG. 3. Scatter plot of ICP versus ONSD. Correlation analysis demonstrated a significant linear correlation between ICP and ONSD. 

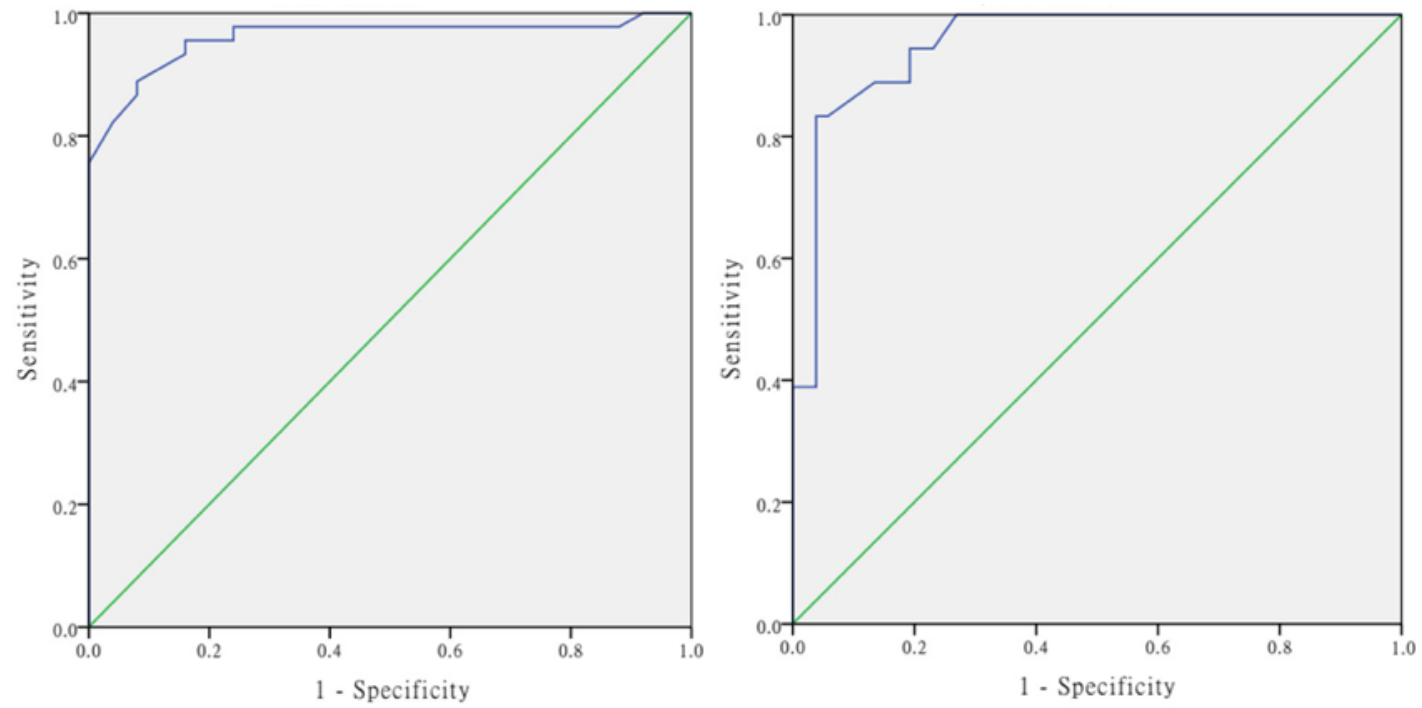

FIG. 4. ROC curve for ONSD with ICP $>13 \mathrm{~mm} \mathrm{Hg}$ (left). ROC curve for ONSD with ICP $>22 \mathrm{~mm} \mathrm{Hg}$ (right). Figure is available in color online only.

high opening pressure of lumbar puncture (US-ONSD > $4.8 \mathrm{~mm}$ and MRI-ONSD > $6.0 \mathrm{~mm}$ ). ${ }^{23}$ Compared with our method, even if the previously reported methods are all noninvasive methods for measuring ONSD for ICP evaluation, the patients are required to undergo CT and MRI examinations. In addition, life-support equipment such as mechanical ventilators limit MRI application. In contrast, the ultrasound used in our method can be performed at the bedside by trained critical care physicians, and quick examinations usually take no more than 4 minutes and can be repeated as needed. US-ONSD decreases or increases immediately following a decrease or increase in ICP, which confirms that ONSD reacts to ICP in real time. ${ }^{7,21}$ However, a few studies revealed that ONSD was not reliable for noninvasive evaluation of ICP. ${ }^{10,31}$ One possible explanation was that the study had a small sample size and selection bias, ${ }^{10}$ the other was that multiple important confounders were not adjusted sufficiently, such as operatordependent measuring errors, acute fluctuation of ICP, and orbital or optic nerve injury. ${ }^{10,31}$

In this study, although ICP $\leq 13 \mathrm{~mm} \mathrm{Hg}$ was obtained by direct ICP monitoring, the corresponding ONSD values were $5.15 \pm 0.52 \mathrm{~mm}$, which were significantly higher than those in healthy adults $(4.09 \pm 0.38 \mathrm{~mm})$. Meanwhile, the critical value of ONSD for elevated ICP $(>13 \mathrm{~mm} \mathrm{Hg}$ ) was $5.48 \mathrm{~mm}$, which was also higher than the previously reported values in healthy adults of $4.8 \mathrm{~mm}^{23}$ and $5 \mathrm{~mm} .^{22}$ The critical value for ICP $>22 \mathrm{~mm} \mathrm{Hg}$ was even higher, i.e., $5.83 \mathrm{~mm}$. DC, a surgical procedure, can effectively control refractory intracranial hypertension through removal of a large section of the skull and opening of the underlying dura mater. ${ }^{17}$ Therefore, even if the patient has brain tissue swelling, with DC treatment the ICP might remain within the normal range. Accordingly, when US-ONSD is used as an indirect index for ICP assessment, ONSD increase may become more pronounced in patients after DC than in patients with closed brain injuries. Indirect measurements of US-ONSD can be performed to indicate possibly elevated
ICP. In case of signs of elevated ICP, the patient should be actively treated by using methods such as ICP reduction therapies, emergency CT or MRI examinations, etc.

The limitations of this study should be mentioned. First, the sample size was small. In addition, only the relationship between ONSD, ICP, and GCS score was observed, with no monitoring of cerebral metabolism and oxygenation or prognostic analysis among patients. ${ }^{15}$ Moreover, this investigation did not include a longitudinal study for repeated measurements of ICPs and ONSDs in these patients. Consequently, this technology cannot provide the exact value of ICP and can be used only to estimate the probability of intracranial hypertension.

\section{Conclusions}

US-ONSD is strongly correlated with ICP measured with invasive techniques and represents a sensitive indicator of increased ICP. In case a patient cannot be moved to the CT or MRI equipment, or the ICP monitor cannot be inserted, indirect measurement of US-ONSD can be performed to possibly indicate elevated ICP.

\section{Acknowledgments}

This work was supported by the Science and Technology Benefit People Project of the Xiamen Science and Technology Bureau (grant no. 3502Z20164062) and the Medical Innovation Project in Fujian Province funded by the Xiamen Health Commission (grant no. 2015-CXB-48).

We would like to express our gratitude to the healthy volunteers and TBI patients who participated in this study. We also thank Ms. Hantee Chen for reviewing the manuscript.

\section{References}

1. Abou El Fadl MH, O'Phelan KH: Management of traumatic brain injury: an update. Neurosurg Clin N Am 29:213-221, 2018

2. Badri S, Chen J, Barber J, Temkin NR, Dikmen SS, Chesnut 
RM, et al: Mortality and long-term functional outcome associated with intracranial pressure after traumatic brain injury. Intensive Care Med 38:1800-1809, 2012

3. Bekerman I, Sigal T, Kimiagar I, Vaiman M: Initial evaluation of the intracranial pressure in cases of traumatic brain injury without hemorrhage. J Neurol Sci 368:285-289, 2016

4. Bratton SL, Chestnut RM, Ghajar J, McConnell Hammond FF, Harris OA, Hartl R, et al: Guidelines for the management of severe traumatic brain injury. II. Hyperosmolar therapy. J Neurotrauma 24 (Suppl 1):S14-S20, 2007 (Erratum in J Neurotrauma 25:276-278, 2008)

5. Calviello L, Donnelly J, Cardim D, Robba C, Zeiler FA, Smielewski P, et al: Compensatory-reserve-weighted intracranial pressure and its association with outcome after traumatic brain injury. Neurocrit Care 28:212-220, 2018

6. Carney N, Totten AM, O'Reilly C, Ullman JS, Hawryluk GW, Bell MJ, et al: Guidelines for the Management of Severe Traumatic Brain Injury, Fourth Edition. Neurosurgery 80:6-15, 2017

7. Chen LM, Wang LJ, Hu Y, Jiang XH, Wang YZ, Xing YQ: Ultrasonic measurement of optic nerve sheath diameter: a non-invasive surrogate approach for dynamic, real-time evaluation of intracranial pressure. Br J Ophthalmol 103:437441, 2019

8. Colton K, Yang S, Hu PF, Chen HH, Stansbury LG, Scalea TM, et al: Responsiveness to therapy for increased intracranial pressure in traumatic brain injury is associated with neurological outcome. Injury 45:2084-2088, 2014

9. Cooper DJ, Rosenfeld JV, Murray L, Arabi YM, Davies AR, D'Urso P, et al: Decompressive craniectomy in diffuse traumatic brain injury. N Engl J Med 364:1493-1502, 2011

10. Gao Y, Li Q, Wu C, Liu S, Zhang M: Diagnostic and prognostic value of the optic nerve sheath diameter with respect to the intracranial pressure and neurological outcome of patients following hemicraniectomy. BMC Neurol 18:199, 2018

11. Geeraerts T, Newcombe VF, Coles JP, Abate MG, Perkes IE, Hutchinson PJ, et al: Use of T2-weighted magnetic resonance imaging of the optic nerve sheath to detect raised intracranial pressure. Crit Care 12:R114, 2008

12. Goeres P, Zeiler FA, Unger B, Karakitsos D, Gillman LM: Ultrasound assessment of optic nerve sheath diameter in healthy volunteers. J Crit Care 31:168-171, 2016

13. Hansen HC, Helmke K: The subarachnoid space surrounding the optic nerves. An ultrasound study of the optic nerve sheath. Surg Radiol Anat 18:323-328, 1996

14. Harary M, Dolmans RGF, Gormley WB: Intracranial pressure monitoring-review and avenues for development. Sensors (Basel) 18:465, 2018

15. Helbok R, Meyfroidt G, Beer R: Intracranial pressure thresholds in severe traumatic brain injury: Con: The injured brain is not aware of ICP thresholds! Intensive Care Med 44:1318-1320, 2018

16. Huang YH, Ou CY: Prognostic impact of intracranial pressure monitoring after primary decompressive craniectomy for traumatic brain injury. World Neurosurg 88:59-63, 2016

17. Hutchinson PJ, Kolias AG, Timofeev IS, Corteen EA, Czosnyka M, Timothy J, et al: Trial of decompressive craniectomy for traumatic intracranial hypertension. N Engl J Med 375:1119-1130, 2016

18. Jiang JY: Head trauma in China. Injury 44:1453-1457, 2013

19. Karvellas CJ, Fix OK, Battenhouse H, Durkalski V, Sanders C, Lee WM: Outcomes and complications of intracranial pressure monitoring in acute liver failure: a retrospective cohort study. Crit Care Med 42:1157-1167, 2014

20. Lele A, Kannan N, Vavilala MS, Sharma D, Mossa-Basha M, Agyem K, et al: Patients who benefit from intracranial pressure monitoring without cerebrospinal fluid drainage after severe traumatic brain injury. Neurosurgery 84:E261, 2018 (Letter)
21. Maissan IM, Dirven PJ, Haitsma IK, Hoeks SE, Gommers D, Stolker RJ: Ultrasonographic measured optic nerve sheath diameter as an accurate and quick monitor for changes in intracranial pressure. J Neurosurg 123:743-747, 2015

22. Ohle R, McIsaac SM, Woo MY, Perry JJ: Sonography of the optic nerve sheath diameter for detection of raised intracranial pressure compared to computed tomography: a systematic review and meta-analysis. J Ultrasound Med 34:1285-1294, 2015

23. Patterson DF, Ho ML, Leavitt JA, Smischney NJ, Hocker SE, Wijdicks EF, et al: Comparison of ocular ultrasonography and magnetic resonance imaging for detection of increased intracranial pressure. Front Neurol 9:278, 2018

24. Raboel PH, Bartek J Jr, Andresen M, Bellander BM, Romner B: Intracranial pressure monitoring: invasive versus non-invasive methods-a review. Crit Care Res Pract 2012:950393, 2012

25. Rajajee V, Williamson CA, Fontana RJ, Courey AJ, Patil PG: Noninvasive intracranial pressure assessment in acute liver failure. Neurocrit Care 29:280-290, 2018

26. Robba C, Cardim D, Tajsic T, Pietersen J, Bulman M, Donnelly J, et al: Ultrasound non-invasive measurement of intracranial pressure in neurointensive care: a prospective observational study. PLoS Med 14:e1002356, 2017

27. Sekhon MS, Griesdale DE, Robba C, McGlashan N, Needham E, Walland K, et al: Optic nerve sheath diameter on computed tomography is correlated with simultaneously measured intracranial pressure in patients with severe traumatic brain injury. Intensive Care Med 40:1267-1274, 2014

28. Seo H, Kim YK, Shin WJ, Hwang GS: Ultrasonographic optic nerve sheath diameter is correlated with arterial carbon dioxide concentration during reperfusion in liver transplant recipients. Transplant Proc 45:2272-2276, 2013

29. Stocchetti N, Maas AIR: Traumatic intracranial hypertension. N Engl J Med 370:2121-2130, 2014

30. Stocchetti N, Poole D, Okonkwo DO: Intracranial pressure thresholds in severe traumatic brain injury: we are not sure: prudent clinical practice despite dogma or nihilism. Intensive Care Med 44:1321-1323, 2018

31. Strumwasser A, Kwan RO, Yeung L, Miraflor E, Ereso A, Castro-Moure F, et al: Sonographic optic nerve sheath diameter as an estimate of intracranial pressure in adult trauma. J Surg Res 170:265-271, 2011

32. Szmygel Ł, Kosiak W, Zorena K, Myśliwiec M: Optic nerve and cerebral edema in the course of diabetic ketoacidosis. Curr Neuropharmacol 14:784-791, 2016

\section{Disclosures}

The authors report no conflict of interest concerning the materials or methods used in this study or the findings specified in this paper.

\section{Author Contributions}

Conception and design: B Chen, Wang, H Chen. Acquisition of data: Wang, $\mathrm{H} \mathrm{Li}, \mathrm{Ji}, \mathrm{Wu}$. Analysis and interpretation of data: B Chen, Wang, K Li. Drafting the article: Wang. Critically revising the article: B Chen, Wang, $\mathrm{K} \mathrm{Li}, \mathrm{H}$ Chen. Reviewed submitted version of manuscript: Wang, K Li, H Li, Ji, Wu, H Chen. Approved the final version of the manuscript on behalf of all authors: B Chen. Statistical analysis: B Chen, Wang, K Li. Administrative/technical/material support: Wang, K Li, H Li, H Chen. Study supervision: B Chen, Wang, H Chen.

\section{Correspondence}

Bin Chen: Xiamen Port Clinic of Xiamen Customs, Fujian, China. drchenbin@126.com. 